\title{
Some memories of Juergen
}

\author{
Rainer K. Sachs
}

Published online: 20 March 2009

(C) The Author(s) 2009. This article is published with open access at Springerlink.com

I worked together with Juergen, off and on, for many years. But my most vivid recollections of him are of my Hamburg postdoc in 1960; he was a very valuable mentor. He was always for clarity and rigor.

To me the most interesting part of his work was his systematic and highly useful clarification of general relativistic hydrodynamics and kinetic theory. It was a real revelation to see such standard concepts as fluid rotation reappear elegantly and rigorously in a fully relativistic setting. Based on his work in kinetic theory, Juergen, P. Geren and I were able to relate local isotropy observations on particles to spatial isotropy and homogeneity of space-time.

Among the many useful lessons I learned from him by example was the importance of being accurate as regards the scope and previous history of a putatively new idea: don't fool yourself that you own something which really belongs to a colleague or predecessor, and don't try to sell more than you own. Not even inadvertently, or by implication, or by judicious silence. Nowadays I see lots of disagreements between groups resulting from all concerned failing to observe those straightforward rulesperhaps because the field, the time, the economic climate, and/or the country I now work in are different. To a bystander, the resulting squabbles supply an amusing spectator sport; but, entertainment aside, I like Ehlers' way better.

In this respect, and many others, I was lucky to have him as a role model. Later my respect for him, as a scientist and as a person, only grew. His work on gravitational lensing was very pleasant to study.

He will be sorely missed. I hope that our younger replacements can and will emulate his scholarship, breadth, clarity, rigor, and integrity.

\footnotetext{
R. K. Sachs $(\varangle)$

University of California, MC 3840, Berkeley, CA 94720, USA

e-mail: rainersachs@yahoo.com; sachs@math.berkeley.edu
} 
Open Access This article is distributed under the terms of the Creative Commons Attribution Noncommercial License which permits any noncommercial use, distribution, and reproduction in any medium, provided the original author(s) and source are credited. 